BULLETIN OF THE GEOLOGICAL SOCIETY OF AMERICA

VOL. 16, PP. 137-150

MARCH 15, 1905

\title{
BEARING OF SOME NEW PALEONTOLOGIC FACTS ON NOMENCLATURE AND CLASSIFICATION OF SEDIMENTARY FORMATIONS
}

\author{
BY HENRY SHALER WILLIAMS
}

(Read before the Society December 29, 1904)

\section{CONTENTS}

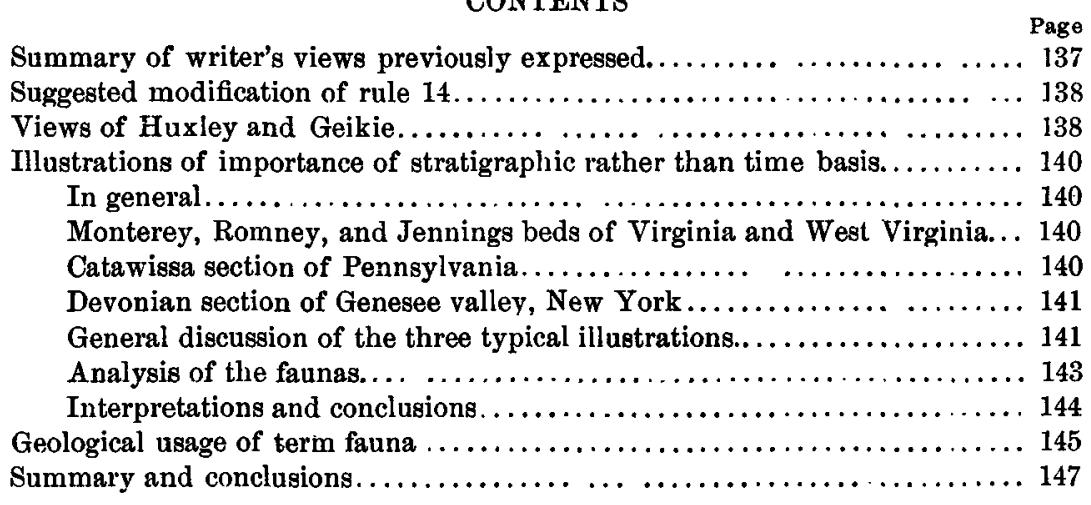

\section{SUMmary of Writer's VieWs PREVIOUSLY EXPRESSED}

It was suggested by the writer, in a paper read before the Geological Society in 1893 , * that duality of nomenclature was desirable in order to discriminate between the divisions of the time scale and those of the formation scale, and later (1902-'3), when the revised rules of nomenclature and classification were being prepared by the United States Geological Survey, $\dagger$ it was still thought that the two scales might be discussed separately if only the criteria of discrimination and the nomenclature were kept strictly distinct. In $1903, \$$ in a paper published in the Bulletin of this Society, the shifting of faunas during the continuance of their biological integrity was shown to be a fact, and it was pointed out that consequent precaution was necessary in using fossils with precision in

* Journal of Geology, vol. 2, pp. 145-160.

† See Twenty-fourth Annual Report U. S. Geol. Survey, pp. 21-27. † See rol. 14, pp. 177-190.

XIX-But... Gzol. Soc. Am., Vol. 16, 1904 
classifying formations. In papers recently completed and now being published as Bulletin 244 of the United States Geological Survey the application of these principles and rules to certain specific cases is set forth in detail.

\section{Suggested Modification of Rule 14}

In all these various papers the attempt was made to employ common nomenclature, as far as practicable, in describing the intricate relationships existing between the fossil faunas and the geological formations under discussion. While revising the proofsheets of Bulletin 244, however, the conviction became positive to the writer that one of the chief difficulties presented by this whole problem of classification and nomenclature of geologic formations arises from the very vague and uncertain use of the word "contemporaneity." In the revised "rules" referred to, although the word "contemporaneity" is dispensed with, the idea is still perpetuated in the phrase "chronologic equivalences." Rule 14 reads as follows :

"The fundamental data of geologic history are (1) the local sequences of formations and (2) the chronologic equivalences of formations in different provinces. Through correlation all formations are referred to a general time scale, of which the units are periods. The formations made during a period are collectively designated a system."

The purpose of the present paper is to raise the question as to whether "chronologic equivalences of formations" are fundamental data of geologic history, and, if not, whether the "fundamental data" indicated by that expression are not in reality the similarities in the fossil faunas of formations of different provinces. In practice is it not also true that formations are not referred to a "general time scale," but to a stratigraphic scale, of which not "periods," but systems, are the units? Considering these queries as answered in the affirmative, why should not rule 14 read as follows:

The fundamental data of geologic history are (1) the local sequences of formations and (2) the similarity of the fossil faunas of the formations of different provinces. Through correlation all formations are referred to a standard stratigraphic scale, of which the units are systems.

\section{Views of Huxley and GeIkIe}

Before discussing the facts of the particular case or bearing on this proposition, the exact point in issue may be emphasized by referring to the argument used by Huxley in 1862 for the substitution of "homataxis" for "contemporaneity." 
Huxley,* in his anniversary address before the Geological Society of London in 1862, said :

" Paleontology has established two laws of inestimable importance: The first, that one and the same area of the earth's surface has been successively occupied by very different kinds of living beings; the second, that the order of succession established in one locality holds good, approximately, in all. . . . As a consequence of the second law, it follows that a peculiar relation frequently subsists between series of strata, containing organic remains, in different localities. The series resemble one another, not only in virtue of a general resemblance of the organic remains in the two, but also in virtue of a resemblance in the order and character of the serial succession in each. There is a resemblance of arrangement; so that the separate terms of each series, as well as the whole series, exhibit a correspondence. Succession implies time; the lower members of a series of sedimentary rocks are certainly older than the upper; and when the notion of age was once introduced as the equivalent of succession, it was no wonder that correspondence in succession came to be looked upon as correspondence in age, or 'contemporaneity.' And, indeed, so long as relative age only is spoken of, correspondence in succession is correspondence in age; it is relative contemporaneity. But it would have been better for geology if so loose and ambiguous a word as 'contemporaneous' had been excluded from her terminology, and if, in its stead, some term expressing similarity of serial relation, and excluding the notion of time altogether, had been employed to denote correspondence in position in two or more series of strata. In anatomy, where such correspondence of position has constantly to be spoken of, it is denoted by the word 'homology,' and its derivatives; and for geology (which, after all; is only the anatomy and physiology of the earth), it might be well to invent some single word, such as 'homotaxis' (similavity of order), in order to express an essentially similar idea."

Huxley further called attention to the fact that it is generally admitted by all the best authorities

" that neither similarity of mineral composition, nor of physical character, nor even direct continuity of stratum, are absolute proofs of the synchronism of even approximated sedimentary strata; while for distant deposits, there seems to be no kind of physical evidence attainable of a nature competent to decide whether such deposits were formed simultaneously, or whether they possess any given difference of antiquity. $\dagger$

" Edward Forbes was in the habit of insisting that the similarity of the organic contents of distant formations was prima facie evidence, not of their similarity, but of their difference of age." $\ddagger$

\section{His conclusion was that}

"There seems, then, no escape from the admission that neither physical geology nor paleontology possesses any method by which the absolute synchronism of two strata can be demonstrated. . . . For areas of moderate extent it is 
doubtless true that no practical evil is likely to result from assuming the corresponding beds to be synchronous or strictly contemporaneous, and there are multitudes of accessory circumstances which may fully justify the assumption of such synchrony. But the moment the geologist has to deal with large areas or with completely separated deposits, then the mischief of confounding that 'homotaxis,' or ' similarity of arrangement,' which can be demonstrated, with 'synchrony,' or 'identity of date,' for which there is not a shadow of proof, under the one common term of 'contemporaneity' becomes incalculable and proves the constant source of gratuitous speculations." *

Discussing this same problem, Geikie $\dagger$ says :

"Strict contemporaneity can not be asserted of any strata merely on the ground of similarity or identity of fossils."

\section{Illustrations of Importance of stratigraphic rather than Time BASIS}

\section{IN GENERAL}

In the bulletin (number 244) referred to two or three particular cases are elaborated which exhibit the importance of using a purely stratigraphic basis in discussing the relations of faunas to formations and of freeing the definition of formations from all time designations. The geologist is referred to the bulletin for details. Only the main facts will be here mentioned. The three cases to which attention is called are as follows:

MONTEREY, ROMNEY, AND JEN NINGS BEDS OF VIRGINIA AND WEST VIRGINIA

First, the faunal combinations and successions in numerous sections cutting through the beds called Monterey, Romney, and Jennings, in Virginia and West Virginia, were analyzed. The facts developed show that at the base of the beds called Romney occasionally a few fossils of the Corniferous and Hamilton of New York, but thereafter the Marcellus, Genesee, and Portage (New York), faunas dominate, to be followed above by Chemung types in cases where these latter are not altogether wanting. In the cases where the Hamilton species appear they are associated with Corniferous forms and lie below the typical black shales called Romney (in Virginia), a formation reported to be the equivalent of the Hamilton and Marcellus.

\section{CATA WISSA SECTION OF PENNSYLVANIA}

The second case is that of the Catawissa section, in central Pennsylvania. After passing above beds which faunally and lithologically are

* Loc. cit., p. xlvi.

† A. Geikie: Text Book of Geology, second edition, 1885, p. 608. 
correlated with the Genesee shales, the beds following, for 1,200 feet, are found to be dominated by an Ithaca fauna. This shows an extreme, so far met with, of the limit of expansion of that fauna.

\section{DEVONIAN SECTION OF GENESEE VALLEY, NEW YORK}

In the third case-the section of the Devonian in the Genesee valley, New York-the Ithaca fauna is entirely wanting, and is there replaced by the Buchiola fauna of the Cashaqua, Gardeau, and Nunda ("Portage ") formations. In the Seneca Lake valley a slight trace of the Ithaca fauna is seen above the Sherburne, but only slight. The Sherburne, with its Buchiola fauna, is followed by the Ithaca ( 400 feet), containing a rich and characteristic fauna, which is then followed by 600 feet of Enfield shales, in which the Buchiola fauna again returns with some modifications.

\section{GENERAL'DISCUSSION OF THE THREE TYPICAL ILLUSTRATIONS}

The case of the Catawissa section, in which the Ithaca fauna occupies an interval of nearly 1,500 feet, wherever fossils occur, is a striking illustration of local difference in range of faunas, since the great thickness of sediinents through which the Ithaca fauna ranges can not be interpreted as increase in thickness of sediments of that particular part of the section, for the sequence of faunules is in its normal order from Genesee to Chemung, but the Ithaca fauna (which is entirely wanting in the Genesee section), there dominates over all associated faunas from near the base to the top of the fossiliferous zone.

The real problem before us may be presented by considering the first case in detail. The chief facts are as follows: In New York there is a standard set of formations occupying a particular portion of the geological column, with which we are all familiar. The formations and their relative positions in the stratigraphic scale are Oriskany, Corniferous, Marcellus, Hamilton, Genesee, ("Portage" or) Nunda, Chemung, and Catskill, together constituting the main part of the Devonian system of that province.

The United States Geological Survey geologic folios for Virginia and West Virginia (take, as examples, the Stanton, Franklin, and Monterey quadrangles) present the same portion of the geological column, divided on a stratigraphic basis into the Monterey, Romney, Jennings, and Hampshire formations.

In the text of the Stanton folio equivalence is implied by a table in which the divisions of the scale, with the names and symbols used in the folio, are (in an adjoining column) filled with names which have been used by various authors: as follows: 


$$
\begin{aligned}
& \text { Dh..... Hampshire formations ...... Catskill. } \\
& \mathrm{Dj} . . \ldots \text {. Jennings formations........ Chemung. } \\
& \text { Dr..... Romney shale.......... Hamilton. } \\
& \text { M..... Monterey sandstone........ Oriskany. }
\end{aligned}
$$

This folio was published in 1894. The Franklin folio, published two years later (1896), included the statement that "the implied correlations with other stratigraphic areas are not necessarily accepted," and under Monterey, in the text, "the fossil remains in this formation are in greater part those which are typical of the Oriskany formation of New York. Under Romney shale, in the same text, appears the statement "the Romney shale contains fossils, including species distinctive of the Hamilton group; those in the lowest beds comprise some species characteristic of the Marcellus," and under Jennings formation "fossils occur in various beds in the Jennings formation and represent the Chemung fauna."

In volume I of the Maryland survey (page 182) "four divisions are recognized in the sequence of Devonian deposits, known as the Monterey, Romney, Jennings, and Hampshire formations."

The inexact nature of this equivalence is indicated in the more detailed "Report for Allegany County, Maryland," in which the old name Oriskany is adopted for the first divisions, and the Romney formation is described as "corresponding in the main with the Marcellus and Hamilton formations farther north" (page 103). The Jennings formation is described as "closely related to the Chemung and Portage of the Pennsylvania and the New York Geological Surveys " (page 106), and the Hampshire formation is said to be "approximately equivalent to the Catskill of the north" (see page 108).

In the case of the Romney formations a twofold paleontological division of the formations is already claimed by Prosser.* It is evident that the classification and nomenclature adopted in the earlier studies of these formations is based on a general homotaxial equivalence and not upon either exact lithologic or paleontologic likeness of the formations or their contents. A more minute examination of the fossil contents demonstrates a lack of parallelism, as is shown by Prosser's paper on the Maryland section and by my Bulletin 244 for the sections farther south in Virginia, West Virginia, Kentucky, and Indiana.

We are therefore obliged to question the propriety of calling the formations of the central Appalachian area, namely, Romney, Jennings, and Hampshire, as "exact synonyms" of Hamilton, Chemung, and Catskill. $\dagger$ In the case in question the facts seem to be established that a general

* Journal of Geology, vol. xii, 1904, pp. 361-378.

†See Bulletin 191, U. S. Geol. Survey, pp. 351, 211, and 186. 
similarity in the sequence of sediments * can be clearly recognized between the sections of Maryland and Virginia and those in the New York and Pennsylvania area of the Devonian.

If lines are drawn across the sections in New York state corresponding to the more strongly marked lines of separation between different types of this sedimentation, they serve to divide off a set of standard formations, and the fossils of these formations have been tabulated to consti: tute the faunas of the formations so established. Thus the Corniferous, Marcellus, Hamilton, etcetera, are established as standard formations. Passing a few hundred miles to the southward, to Virginia, similar lines may be drawn across the same general series of Devonian sediments to make three divisions corresponding in a general way with the more striking divisions of the New York section; but they do not agree in detail, in thickness, or in fossil contents. While, therefore, it may be convenient to speak of them as occupying the same general place in stratigraphic succession with the New York formations indicated as correlated with them, the differences in all of their visible characters are sufficient to forbid calling them the same formations, or even chromologic equivalents.

\section{ANALYSIS OF THE FAUNAS}

The analysis of the faunules, as gathered in Bulletin 244, shows that the fossil faunas contained in the strata classified in the folios as Romney, Jennings, and Hampshire are not the same as those of the New York formations with which they are compared, namely, the rocks belonging to the part of the column called Romney, in central and southern Virginia, contain chiefly the faunas found in New York in the Marcellus, Genesee, and Nunda ("Portage"), with only traces of the Hamilton fauna near their base. The Jennings formation does, in many cases, hold a "Chemung fauna;" but as it is followed southward along the Appalachian this latter fauna is lacking, and the succession is then directly from the black Romney shales upward into a Mississippian, or lower Carboniferous, fauna, occurring in the shales after the black shale sediments ceased, while the fauna of the Genesee-Portage formations of New York chiefly fills the lower interval. The evidence indicates that when the specific Hamilton, Ithaca, and Chemung faunas are wanting in the sediments of the middle Appalachian region a fauna of the type (found intercalated between them in the New York area) seen in the Marcellus, Genesee, and Nunda ("Portage") of New York, dominates

* Passing from limestone through black shales, fine and evenly laminated ; then coarser, thin bedded, argillaceous shales and sandistones; next sandstones of thicker and more frequent occurrence, running into coarser cross-bedded sandstone with red beds occasionally interspersed, and finally coarser sandstones with occasional conglomerates. 
throughout that portion of the sections where the former faunas are expected.

This interpretation of the facts is associated with other evidence pointing to no unconformity or culling out of parts of the stratigraphic series, but rather to a continuous, uninterrupted sedimentation, in which the fossils so prominent at several particular horizons in New York are actually wanting, and their place in the stratigraphic series is occupied by other faunas, which in New York occupy intermediate positions.

\section{INTERPRETATIONS AND CONCLUSIONS}

Thus, if we interpret like faunas into equivalence of formation we are obliged to say that in central and southern Virginia the Genesee and Portage faunas range through the main part of the Romney and part of the Jennings formations, and the Jennings holds a pure Chemung fauna only in its upper or central part; but in no case do the fossil contents give a basis for saying that the Romney is the exact equivalent of the Hamilton or Marcellus, or both, nor that the Jennings is the exact equiv alent of the Chemung, when by equivalence is meant the same fauna or fossil contents. Equivalence is therefore a correct term to apply to the formation names united by a hyphen only when the inference is drawn that the beds were deposited at the same period of time (contemporaneity), since the lithology, stratigraphy, and fossils are all diverse for each couplet. Therefore it can not be claimed that there is either lithologic, stratigraphic, or paleontologic equivalence. Of course, it is to be expected that at any particular epoch of geologic time in different regions of the earth formations were being made which present no agreement in lithology or in fossils; but when we come to deal with such formations as geologic units, define them in scientific terms, and represent their outcrops on geologic maps, it is all-important to restrict the terms of definition to observable facts, and to classify and name formations as the same only when the terms of their definition agree. In the case before us the terms of definition disagree. This fact alone is sufficient reason for applying different names to the stratigraphic divisions in Virginia (Romney, Jennings, and Hampshire) which are correlated in a general way with divisions called Marcellus, Hamilton, Chemung, etcetera, in New York. It also follows from what has been said that equivalence, when used in a chronologic sense, may or may not mean equivalence of all or any of the criteria used in defining the formation. A formation may be said to be equivalent in the chronologic sense (that is, formed at the same time) when the lithology and paleontology are entirely discordant, and it may be true, but the evidence of the truth of the statement is complex and not discernible by simple 
examination of the formations themselves. It is on account of this complexity of the proofs and the varying opinions as to both the value and the inferences regarding contemporaneity to be drawn from any or all the visible evidence supplied by the formations as geologic units that leads me to a conviction that we must dispense with any association of time with the definition of a stratigraphic formation, and use, in discriminating, defining, and classifying them, only those marks which are visible and can be measured, located, and described in scientific terms.

In all such cases as in the one cited the facts are stated, when it is said that correlation with the Devonian system is recognized in the Virginia formations, Monterey, Romney, Jennings, and Hampshire, that their division is recognized in the Virginia region on a basis of lithologic difference, and that the homotaxial relations of these formations, roughly speaking, correspond to the Oriskany, Hamilton, Chemung, and Catskill of the New York classification. It is misleading, however, to speak of the several pairs of formations as "chronologic equivalents." The evidence is not in hand to prove that they are or are not; their chronologic relations are still to be established.

If any of the fossils occurring in the Hamilton formation, as defined in central New York, were strictly confined in their vertical range to the limits marking the base and the top of the portion of the section described as Hamilton, the case would be different. In such a case it would be possible to infer that the same fossils elsewhere could be interpreted into contemporaneity of sedimentation. But the facts accumulated disprove such an assurnption; and until the total stratigraphic range for fossils is ascertained for each area of distribution, and the question as to whether that range is different in separate regions is established, fossils can not be used as proof of the contemporaneity of short sections of the stratigraphic column which happen locally to hold the same species.

\section{Geological Usage of Term Fauna}

A word may be added to explain the geological usage of the term fauna.

In literature there has grown up from the old conception of separate creations and the peopling of the earth with separate organism at the beginning of each geological period the idea that the fossils found in a formation are peculiar to the formation-are "leit fossilien." Thus the time when a formation was formed and the fossils contained in the formation have come to be regarded as correlative terms. The time scale is thus regarded as only another mode of indicating the strati- 
graphic scale. This conception is fully elaborated in the early reports of the International Geological Congress, and the divisions of the time scale-"era," "period," "epoch," "age "-are there regarded as strict equivalents of "group," "system," "series," "stage," so far as their application to the facts of stratigraphy is concerned.

Most geologists, having been accustomed to use these terms as interchangeable, may find difficulty in recognizing the bondage to old ideas which this usage enforces.

Although the American geologists have adopted another system of nomenclature, the influence of this implication is still apparent in the confusion of chronologic language with physical facts. To avoid this confusion the writer began several years ago to classify fossils into faunas, irrespective of the formational limits to which they were supposed to be restricted, and the fact has clearly developed that formational limits do not by any means mark the range of either the fossils of a formation or of the integrity of associations of species into groups of faunas. Thus the fact has developed that the local formation which in a local section contains a diagnostic fauna is limited below and above, not by the beginning and ending of the life history of the particular fauna, but only by the beginning and ending of the fauna of the particular locality where the sedimentation took place. In another locality, it may be not far distant, the same fauna may appear at a lower or higher stratigraphic horizon and in its integrity. It may also reappear in the same locality after having been entirely absent from the sediments for a period of time represented by hundreds or thousands of feet of sediments, and, in such cases the fauna is more apt to show disturbance of its contents than when the whole fauna has become shifted. This explanation will make it clear why the presence of a species of the Hamilton fauna in the Romney of Maryland, Virginia, Kentucky, or Indiana does not furnish proof of the Hamilton period, epoch, or even formation, as those terms are used in current literature.

The fossils of the Hamilton formations of New York undoubtedly have a definite stratigraphic range, which we may hope to determine in the future, but that will not change the stratigraphic limits of that formation. It will, however, enlarge the chronologic limits expressed by the fauna of the Hamilton formation. The facts already in hand show that the New York Marcellus below and the Nunda ("Portage") and part of the Chemung formations above are included in the time period through which the Hamilton fauna ranges. In order to distinguish the names of these two units the fauna of the Hamilton formation of New York is called the Tropidoleptus fauna. 
While it is practicable to establish homotaxial equivalence between a particular local fauna and the general fauna of some particular system (and perhaps to locate the fauna in its lower, middle, or upper portion), it does not follow that a closer degree of equivalence can be established between two local faunas by the same criteria. In the first case the general equivalence may be proven in a case in which few or none of the species are identical species, but even in case the identity of species in two formations is proven, the equivalence so established is only within the limits of the known range of the species of the fauna. This range in most known cases is at least as much as a third of the thickness of the system in which it belongs. We are therefore forced to the conviction that in the correlation of local formations the same species of fossils alone (when so much as 50 miles of distance separates their stations) can not be relied on for establishing more than a general homotaxial relation of the formations compared. The limit of range of every species is far greater, both above and below, than is indicated by any local formation in which it occurs. Geologists have already recognized the fact that uniform conditions of sedimentation are local as well as temporary, and the same principle must be applied to fossils. The vertical range of individual species, as well as that of their combination into faunules, varies greatly with the local conditions that prevailed during the life of the species, and thus their place in the vertical stratigraphic column varies with geographic distribution.

\section{Summary and Conclusions}

What has been said refers to the geologic formation as a particular mass of stratified rocks occupying a particular position or horizon in the geological column and whose geographical extent may be determined. What I am urging is that greater clearness of description and accuracy of statement will be attained in describing such formations if all reference to time relations be dispensed with. Let us speak of them as "homotaxial;" but when their lithologic or paleontologic characters differ, let us say so and call the formations by different names and indicate their general relations to the standard scale simply by bracketing them as Devonian, or, if the correlation be more definite, as Eodevonian or Mesodevonian, as the case may be, but not as the equivalent of a formation which we regard as formationally distinct.

The next point I have to make is that in the definition, and particularly in the mapping, of formations it is important to make the definition so that the mass not only can be located and recognized by the terms of the definition, but so that its limits can be distinctly recognized 
in the field. In the examples selected the line between the Romney and Jennings and that between Jennings and Hampshire are frankly described in the folios as so indefinite as to be recognized with difficulty. Geologists are not always so frank on this point when they return from the field. The evidence brought forward by the analysis of the faunas shows that if the lithologic transitions are perplexing in the case in question the sequence of faunules is also unsatisfactory for establishing precise lines of separation between two contiguous formations.

In the course of the present investigations the recurrence of faunules has become an established fact, and not only for a short vertical distance through the beds, but recurrences of faunules of the same fauna have been traced for a thickness of hundreds and in one region up to about 2,000 feet of sediments in which intercalation of entirely distinct faunas has taken place. With these facts in view, we are deceiving ourselves when we presume that half a dozen fossils of particular species occurring together determine the stratigraphic horizon, so that the local line below or above them may always serve for the limits of the formation. The fossils do indicate a general portion of the geologic column, but it is only indefinitely, somewhere within one or two thousand feet of thickness of strata. They do not alone establish equivalence of formation, when by formation is meant a definite part of the stratigraphic column set off by definite boundaries below and above.

It may also be stated that the sharper the paleontologic transition from one fauna to another (in ascending through a series of strata) the stronger is the certainty that the local limit thus assigned is not the stratigraphic equivalent of a similar sharp transition between the same two faunas elsewhere. The very fact of the definiteness of the faunas is also sure evidence that they had lived a long time before the first trace of them in the section and lived a long time after the highest traces in the local section, and the sharpness of the transition from the one to the other is evidence that the superior fauna was not derived from the lower one, but that the local succession is a result of movement and replacement of the faunas themselves.

The conclusion of the matter to which the facts force us is that not only lithologic but paleontologic facts are local. The fossil contents may completely change, often very rapidly and often in a few miles. The fossils undoubtedly are the means on which we chiefly rely for determining that kind of equivalence which is called contemporaneity and homotaxy ; but it must not be overlooked that the characters of fossils (that is, the marks by which species and genera are distinguished) are extremely long ranging. Fossil species were not ephemeral things which changed every few feet of thickness of sediments. 
In the use of fossils, for determining the geologic horizon of the formations containing them, the essential fact open to investigation is the presence or absence of the fossils themselves. The presence of individual fossils indicates, not some narrowly limited horizon, but a general portion of the stratigraphic scale represented by the system or by a large subdivision of it. By close discrimination characters of narrower vertical range can be detected, but up to the present time very few characters of fossils are known whose vertical range-limits are so narrow as to indicate an horizon of less than about a third of a standard system.

Certain modifications of current usage are suggested by the facts here presented, which may be expressed by the following recommendations :

In seeking to perfect the rules governing nomenclature and classification of sedimentary geologic formations should not the following principles be applied :

1. The abolition from the nomenclature, definition, and classification of geologic sedimentary formations of all reference to time or time relations.

The application of this rule would result in the rewording of rule 14 of the "Revised Rules," as suggested at the opening of this paper.

2. The adoption of lithologic characters, stratigraphic position, and paleontologic contents as three (at least) chief means for discriminating and defining sedimentary formations.

3. The revision of technical nomenclature in the following particulars: In the place of time scale use the term stratigraphic scale; in place of contemporaneity use homotaxy; in place of age, in its general sense, apply the term horizon'with the definite and technical meaning of position in the vertical stratigraphic scale; in place of period use the term system; it has already become common practice to speak of group, series, and formation on this general principle; in the place of earlier or older adopt the terms inferior, lower, subjacent, or underlying; in place of younger or later adopt the terms superior, superjacent, overlying; and in general in the selection of descriptive terms to apply to sedimentary formations, both in definition and correlation, employ physical characters (such as composition, texture, structure), special dimensions, and position in a vertical stratigraphic column in place of any chronologic terms, these latter, so far as formations are concerned, being inferential, not observable, and incapable of accurate application on account of the wide divergence of opinion as to the modes of their determination.

In proposing these changes in usage it should be stated that it is not intended in any sense to exclude the consideration of time relations in geological discussions, but rather to remove from the definition and discrimination of formations any reference to their supposed time relations 
in order that actual history and time relations in geologic history may be studied with a greater precision and freed from that vague prejudgment which naturally arises from confusing chronologic with physical and spacial ideas.

It may be mentioned further that in the discussion of fossils, faunas, and faunules time relations must be considered, since heredity and evolution are time questions; but for such discussions the formations and their exact position in a stratigraphic scale must be first established, independently of the fossils they contain, before the historical relations of the fossil faunas can be accurately discriminated. In the same way that physical geography must stand on a basis of physical definition entirely independent of political boundaries or political characters, so must formational geology derive its definitions, terminology, and classification from the characters which are actually possessed by formations and which can be examined, measured, and defined before the history of the organisms preserved in them can be accurately determined and before questions of the absolute time relations of geologic events can be established on a firm basis of fact. 
Downloaded from gsabulletin.gsapubs.org on August 12, 2015 


\section{Geological Society of America Bulletin}

\section{Bearing of some new paleontologic facts on nomenclature and classification of sedimentary formations}

HENRY SHALER WILLIAMS

Geological Society of America Bulletin 1905;16, no.

$1 ; 137-150$

doi: 10.1130/GSAB-16-137

Email alerting services

Subscribe

Permission request click

www.gsapubs.org/cgi/alerts to receive free e-mail alerts when new articles cite this article

click

www.gsapubs.org/subscriptio ns/ to subscribe to Geological Society of America Bulletin

click

http://www.geosociety.org/pu bs/copyrt.htm\#gsa to contact GSA

(C) 1905 Geological Society of America

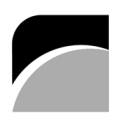

THE GEOLOGICAL SOCIETY OF AMERICA 
Copyright not claimed on content prepared wholly by U.S. government employees within scope of their employment. Individual scientists are hereby granted permission, without fees or further requests to GSA, to use a single figure, a single table, and/or a brief paragraph of text in subsequent works and to make unlimited copies of items in GSA's journals for noncommercial use in classrooms to further education and science. This file may not be posted to any Web site, but authors may post the abstracts only of their articles on their own or their organization's Web site providing the posting includes a reference to the article's full citation. GSA provides this and other forums for the presentation of diverse opinions and positions by scientists worldwide, regardless of their race, citizenship, gender, religion, or political viewpoint. Opinions presented in this publication do not reflect official positions of the Society.

\section{Notes}

(C) 1905 Geological Society of America

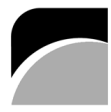

THE GEOLOGICAL SOCIETY OF AMERICA 